\title{
Literature Review: Arsitektur Sistem Penentuan Posisi di Dalam Ruangan
}

\author{
Eko Suripto Pasinggi, Srivan Palelleng, Ferayanti Boas Gallaran \\ Program Studi Teknik Informatika \\ Universitas Kristen Indonesia Toraja \\ Tana Toraja, Indonesia \\ ekopasinggi@ukitoraja.ac.id, srivan_palelleng@ukitoraja.ac.id, \\ ferayanti@ukitoraja.ac.id
}

\begin{abstract}
ABSTRAK
Sistem Penentuan Posisi merupakan salah satu sistem yang banyak dikembangkan saat ini. Hal tersebut seiring dengan konsep teknologi masa depan yang menerapkan context-awareness. Paper ini menyajikan gambaran mengenai beberapa teknik, teknologi dan beberapa contoh sistem yang telah ada saat ini. Disampaikan juga beberapa parameter untuk mengevaluasi sebuah positioning system untuk dapat membandingkan sistem-sistem yang telah ada.

Kata kunci-positioning, triangulasi, fingerprinting, proximity, indoor positioning
\end{abstract}

\section{PENDAHULUAN}

Ubiquious computing merupakan sebuah konsep teknologi masa depan yang saat ini sedang dikembangkan melalui berbagai penelitian. Salah satu komponen ubiquitous computing adalah context-aware system, yaitu sistem bekerja berdasarkan konteks. konteks merupakan informasi yang digunakan untuk menyatakan karakteristik sebuah entitas dan bersifat relevan terhadap interaksi pengguna dan aplikasi [1]. Lokasi merupakan salah satu aspek konteks yang penting dan sering digunakan [2]. Ubiquitous system harus memperoleh informasi konteks dengan tepat untuk menyediakan layanan yang sesuai [3]. Konsep 
location-aware telah diimplementasikan untuk berbagai kebutuhan seperti aplikasi untuk menunjukkan boarding gate kepada penumpang pesawat, membantu seorang siswa menemukan ruang kelas, membantu menemukan sebuah produk saat berbelanja di supermarket, pemandu perjalanan, pendeteksian lokasi produk pada gudang, pelacakan peralatan medis di rumah sakit, dan pendeteksian posisi petugas pemadam kebakaran dalam gedung yang terbakar [4][5].

Teknologi Global Positioning System (GPS) adalah teknologi penentuan lokasi yang paling luas digunakan saat ini dan menjadi teknologi standar untuk penentuan lokasi. GPS mampu memberikan tingkat akurasi yang tinggi untuk penggunaan di luar ruangan, namun akan menemukan tantangan yang signifikan untuk penggunaan di dalam ruangan [6][7]. GPS tidak dirancang untuk penggunaan di dalam ruangan karena kondisi tersebut tidak memungkinkan terjadinya transmisi yang tidak terhalang (Line of Sigh) antar perangkat dan satelit [8]. Saat ini banyak penelitian menunjukkan bahwa penentuan lokasi di dalam ruangan memungkinkan untuk dilakukan dengan menggunakan teknologi wireless lainnya, misalnya WLAN, Infrared, dan RFID [6] [9] [10]. Sistem yang khusus dirancang untuk untuk menentukan posisi di dalam ruangan ini sering disebut Wireless Indoor positioning system (WIPS).

Sebuah WIPS dapat menyediakan beberapa jenis informasi sesuai dengan kebutuhan pengguna. Informasi tersebut dapat berupa lokasi absolut, relatif atau proximity [5][9][11]. Informasi absolut dinyatakan dalam bentuk koordinat, misalnya koordinat GPS. Informasi relatif diperoleh berdasarkan referensi sebuah objek lain, misalnya objek A berada di sebelah kiri objek B. Informasi proximity dinyatakan bentuk simbolik, misalnya dapur, kantor, dan kelas. Sebuah sistem juga dapat mengombinasikan jenis informasi untuk memperkaya informasi, misalnya sebuah lokasi absolut ditambah dengan informasi proximity sebagai tambahan informasi.

WIPS dapat kategorikan berdasarkan beberapa kriteria. Berdasarkan penggunaan infrastruktur yang telah ada, WIPS dapat dikelompokkan menjadi infrastruktur-based dan non-infratruktur-based. Penggunaan infrastruktur yang telah ada dapat menurunkan biaya, namun di sisi lain pembangunan infrastruktur 
khusus dapat memberikan kebebasan desain yang bisa berpengaruh pada kualitas sistem.

Kriteria lain yang dapat digunakan adalah arsitektur atau topologi. Sebuah WIPS minimal memiliki dua buah komponen: komponen transmiter dan komponen penghitung. Berdasarkan arsitektur, WIPS dapat dikelompokkan menjadi self-positioning dan remote-positioning. Pada arsitektur self-positioning, perangkat mobile akan menerima sinyal dari beberapa transmiter. Berdasarkan sinyal yang diterima tersebut, perangkat mobile akan melakukan kalkulasi. Sedangkan pada arsitektur remote-positioning, perangkat mobile berperan sebagai transmiter dan beberapa perangkat pengukur menerima sinyal tersebut. Hasil pengukuran dikumpulkan pada sebuah master station untuk dilakukan perkiraan posisi.

\section{TEKNIK PENENTUAN POSISI}

Tiap WIPS menggunakan sebuah prinsip kerja dan algoritma tertentu untuk menentukan posisi. Ada tiga teknik dasar untuk melakukan penentuan lokasi: triangulasi, fingerprinting, dan proximity [11]. teknik triangulasi dan fingerprinting dapat memberikan jenis informasi absolut, relatif, dan proximity, sedangkan teknik proximity hanya dapat memberikan jenis informasi proximity.

\section{A. Teknik Triangulasi}

Teknik triangulasi menggunakan prinsip geometri untuk melakukan penentuan lokasi. Perhitungan dilakukan berdasarkan pada beberapa titik referensi. Kualitas penentuan posisi sangat dipengaruhi oleh posisi titik referensi [12]. Triangulasi dibagi menjadi sub-kategori laterasi dan sub-kategori angulasi.

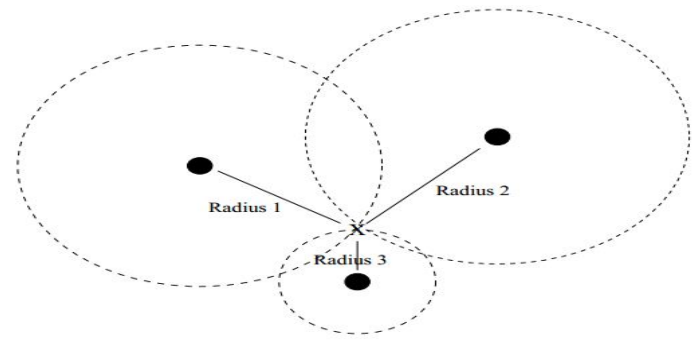

Gambar 1. Teknik Laterasi [13] 
Teknik laterasi menghitung posisi sebuah objek berdasarkan jarak terhadap beberapa titik referensi (lihat Gambar 1). Penentuan posisi dalam dua dimensi (2D) membutuhkan minimal tiga titik referensi dan dalam tiga dimensi (3D) dibutuhkan minimal empat titik referensi. Untuk memperoleh jarak antar objek dan titik referensi dapat digunakan beberapa parameter.

\section{Time of Arrival (TOA)}

Jarak antar objek dan referensi dihitung berdasarkan waktu propagasi (signal propagation time) yang dikirimkan dari titik referensi ke objek [14]. Prinsip geometri yang digunakan diperlihatkan pada Gambar 1, r1,r2,r3 merupakan jarak hasil perhitungan berdasarkan TOA. Titik potong ketiga lingkaran menyatakan perkiraan lokasi objek.

\section{Recieve Signal Strength (RSS)}

Perhitungan jarak didasarkan pada nilai power transmit dan nilai power yang diterima (RSS). Berdasarkan kedua nilai tesebut diperoleh power yang hilang (signal propagation loss), yang kemudian digunakan untuk memperkirakan jarak. Prinsip penentuan lokasi yang digunakan sama dengan prinsip pada TOA, yang membutuhkan minimal tiga titik referensi.

\section{Roundtrip Time of Flight (RTOF)}

Parameter yang digunakan adalah waktu yang dibutuhkan oleh sinyal untuk kembali ke transmiter [14]. selanjutnya digunakan perhitungan yang sama dengan teknik TOA. Teknik ini dikembangkan untuk mengatasi kekurangan pada TOA yang memerlukan sinkronisasi antar perangkat yang terlibat.

Teknik angulasi dikenal juga dengan nama AOA (Angle of Arrival). Berbeda dengan teknik laterasi, teknik angulasi menggunakan sudut untuk menentukan posisi objek. Dibutuhkan minimal dua sudut antar objek dengan referensi dan sebuah jarak antar dua titik referensi seperti yang ditampilkan pada Gambar 2. Pada implementasinya, arah Utara sering digunakan sebagai referensi 0 derajat. 


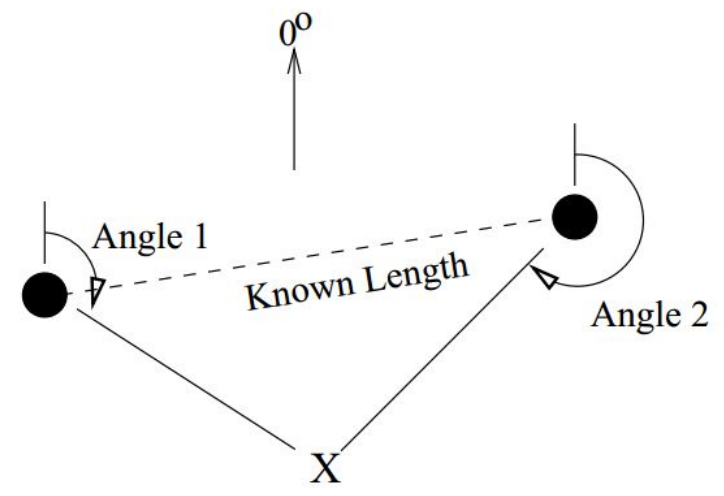

Gambar 2. Teknik Angulasi [15]

\section{B. Teknik Fingerprint}

Teknik ini mengacu pada teknik yang mencocokkan fingerprint/fitur sinyal pada sebuah lokasi dengan data hasil pengukuran. Terdapat dua fase dalam penggunaan teknik ini: fase offline dan fase online. Pada fase offline dilakukan survei pada lokasi. Data yang diambil berupa koordinat/label disertai signal strength dari beberapa transmiter. Dan pada fase online, yaitu pada saat penentuan lokasi, RSS yang diterima dicocokkan dengan kumpulan data yang diperoleh pada fase offline.

Setidaknya ada lima Algoritma yang dapat digunakan untuk melakukan perhitungan penentuan lokasi pada teknik ini: metode probabilistik, $k$-nearestneighbor ( $\mathrm{kNN})$, neural networks, support vector machine (SVM), and smallest Mvertex polygon (SMP).

\section{Teknik Proximity}

Pada teknik ini, penentuan lokasi target berdasarkan pada sebuah lokasi atau area yang diketahui. Teknik proximity membutuhkan beberapa detektor pada lokasi yang ditentukan. Pada saat sebuah target terdeteksi oleh sebuah detektor maka lokasi target tersebut dianggap berada dalam area yang dicakup oleh detektor tersebut [16]. Teknik ini tidak memberikan lokasi absolut atau relatif namun dapat memberikan keakuratan untuk mengetahui sebuah objek berada pada sebuah wilayah tertentu atau tidak. 


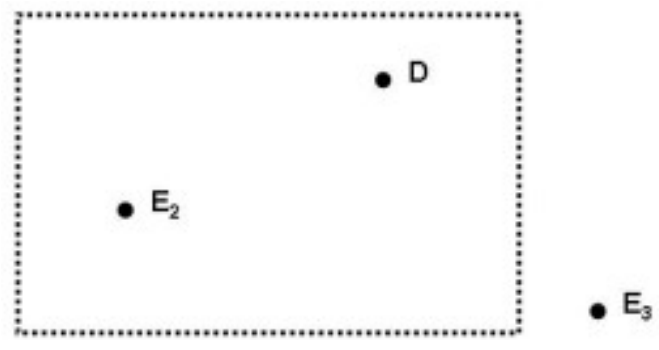

Gambar 3. Teknik proximity [8]

Terlihat Gambar 3, E2 dan E3 adalah target dan kotak adalah area dari detektor D. Berdasarkan keadaan pada gambar, E2 terletak dalam area detektor D, sedangkan E3 tidak.

\section{WIRELESS INDOOR POSITIONING SYSTEMS}

\section{A. RFID Positioning System}

RFID (Radio Frequency Identification) merupakan sebuah teknologi yang memanfaatkan gelombang radio untuk melakukan identifikasi. RFID terdiri dari RFID tag untuk menyimpan informasi ID dan RFID reader untuk membaca isi dari sebuah tag. Ada dua jenis teknologi RFID, pasif RFID dan aktif RFID.

Pada pasif RFID, tag bertindak sebagai reciever, berukuran kecil dan relatif murah, namun dengan jangkauan area yang sempit. Sedangkan pada aktif RFID, tag bertindak sebagai tranciever yang secara aktif mentransmisikan informasinya. Harga tak aktif lebih mahal namun pada sisi lain dapat memberikan area cakupan yang lebih luas. Sistem yang menggunakan RFID harus membuat infrastruktur sendiri yang dirancang khusus untuk kebutuhan tersebut.

SpotOn [17] bekerja berdasarkan RSS untuk penentuan lokasi dalam tiga dimensi (ruang). SpotOn dapat memberikan informasi lokasi absolut dan relatif.

LANDMARC [18], sebuah prototipe yang dirancang menggunakan aktif tag. Untuk meningkatkan akurasi tanpa menambahkan reader, sistem ini meningkatkan jumlah referensi untuk membantu kalibrasi. LANDMARC bekerja berdasarkan RSS yang diterima oleh reader dari tag dan mengadopsi metode kNN untuk melakukan kalkulasi lokasi tag. Memiliki tingkat akurasi sekitar 1-2 meter untuk 50 percentil. 


\section{B. WLAN Positioning Systems}

Teknologi WLAN adalah teknologi yang sangat populer dan banyak diimplementasikan di area publik, seperti kampus, mall, rumah sakit, kantor, dll. WLAN Positioning System memanfaatkan infrastruktur yang telah ada tersebut yang menyebabkan biaya infrastruktur menjadi rendah.

RADAR [19] menerapkan teknik fingerprinting dan algoritma kNN untuk menentukan posisi. RADAR mampu memberikan akurasi 2-3 meter dan 50 percentil.

Horus System [20] menerapkan teknik fingerprinting dan metode probabilistik serta teknik clustering untuk mengurangi beban komputasi. Hasil percobaan menunjukkan akurasi mencapai 2.1 meter pada tingkat presisi $90 \%$.

Dalam [21], Battiti et al. Menggunakan metode neural-network clasifier dengan menerapkan multilayer perceptron (MLP) dan one-step secant (OSS) training method. Hasil percobaan menunjukkan bahwa dengan hanya lima sampel sistem dapat memperoleh akurasi 3 meter dan dengan peningkatan jumlah sampel sistem ini dapat menghasilkan tingkat akurasi hingga 1.5 meter.

COMPASS [22] mengombinasikan WLAN dan kompas digital untuk meningkatkan akurasi. COMPASS menggunakan informasi RSS dan metode probabilistik. Penggunaan kompas memberikan informasi tambahan berupa orientasi pengguna. Berdasarkan pengujian dihasilkan tingkat akurasi 1.65 meter.

Dalam [23] digunakan teknik fingerprinting dengan memanfaatkan sinyal RSS dari perangkat WLAN. Dalam penelitian tersebut dilakukan variasi nilai $k$ dalam penggunaan Algoritma kNN. Tingkat akurasi terbaik yang dihasilkan sebesar 1,45 m menggunakan nilai $k=4$ dan 5. Pada tingkat akurasi 2 meter, sistem mampu memberikan presisi $84 \%$.

\section{WSN Positioning Systems}

Sensor-based positioning terdiri dari banyak sensor yang diletakkan pada tempat ditentukan. Hasil pengukuran yang diambil oleh sensor-sensor ini dapat diperoleh lokasi sebuah objek. 
OPT (Online Person Tracking) [24] menggunakan RSS untuk mendapat jarak antar transmiter dan reciever sensor. Berdasarkan data tersebut digunakan teknik triangulasi dan algoritma weighted minimum mean square error (WMMSE) untuk memperoleh posisi perkiraan. OPT membutuhkan biaya yang rendah karena menggunakan infrastruktur sensor network yang telah terpasang. Hasil pengujian memberikan tingkat akurasi 1.5 - 3.8 meter.

\section{Bluetooth Positioning Systems}

Teknologi bluetooth didesain dengan spesifikasi untuk WPAN dengan jangkauan mencapai $100 \mathrm{~m}$ (Bluetooth 2.0). bluetooth telah ditanamkan pada berbagai perangkat mobile dan dengan harga chipset yang murah dapat dihasilkan sebuah positioning system yang biaya rendah.

BLPA (Bluetooth Local Positioning Application) [25] menggunakan informasi RSS untuk menentukan jarak dengan objek dan Extended Kalman Filter (EKF) untuk menghitung posisi dalam 3D. Hasil pengujian menunjukkan tingkat akurasi sebesar 3.76 meter.

Fahrudin et al. [26] merancang sebuah sistem penentu posisi berbasis teknologi bluetooth. Sistem tersebut memanfaatkan iBeacon sebagai transmitter dan teknologi bluetooth generasi 4 (Bluetooth Low Energy) yang tertanam pada smartphone sebagai receiver. Sistem ini menggunakan metode trilaterasi dengan algoritma three border positioning dan menghasilkan tingkat akurasi sebesar 1,13 meter.

\section{EVALUASI}

Untuk melakukan evaluasi terhadap sebuah sistem penentuan lokasi dibutuhkan beberapa parameter sebagai pembanding. Menurut [5], [8] dan [11] evaluasi dapat menggunakan parameter akurasi, presisi, dan biaya.

\section{Akurasi}

Sebagai sistem yang memberikan informasi berupa lokasi, kriteria yang paling dibutuhkan adalah tingkat ketepatan atau akurasi penentuan lokasi. Akurasi dinyatakan dalam bentuk tingkat galat yang dapat ditentukan dengan 
membandingkan antara lokasi perkiraan dan lokasi sesungguhnya. Galat dinyatakan dalam satuan jarak, misalnya tingkat galat 1 meter berarti perbedaan antar lokasi perkiraan dengan lokasi sesungguhnya adalah 1 meter.

2. Presisi

Presisi menyatakan tingkat kemungkinan suksesnya perkiraan yang berdasar pada tingkat akurasi yang ditentukan. Presisi menggambarkan konsistensi kerja sebuah sistem. presisi dapat dinyatakan dalam bentuk persentase, misalnya akurasi 1 meter dan presisi $90 \%$ berarti sistem dapat melakukan perkiraan lokasi dengan akurasi 1 meter sebanyak 90\% dari total percobaan.

3. Biaya

Biaya sebuah WIPS terdiri dari beberapa komponen: komponen infrastruktur, komponen perangkat pengguna, komponen instalasi dan perawatan.

Sistem yang telah dijelaskan akan dibandingkan berdasarkan ketiga kriteria evaluasi tersebut. Tabel 1 menampilkan perbandingan antar sistem berdasarkan teknologi wireless yang digunakan, Teknik/ Algoritma dan kriteria evaluasi. Perbandingan tersebut tidak dapat menjadi acuan untuk menentukan sistem yang lebih baik karena tidak diujikan dalam lingkungan yang sama.

Tabel 1. Perbandingan beberapa sistem

\begin{tabular}{|l|l|l|l|l|l|}
\hline Sistem & Teknologi & Teknik/Algoritma & Galat & Presisi & Biaya \\
\hline SpotOn [17] & RFID & Lateration & $3 \mathrm{~m}$ & - & Rendah \\
\hline LANDMARC [18] & RFID & kNN & $<2 \mathrm{~m}$ & $50 \%-1 \mathrm{~m}$ & Rendah \\
\hline RADAR [19] & WLAN & $\mathrm{kNN}$ & $3-5 \mathrm{~m}$ & $\begin{array}{l}50 \%-2,5 \mathrm{~m} \\
90 \%-5,9 \mathrm{~m}\end{array}$ & Rendah \\
\hline Horus [20] & WLAN & Probabilistik & $2 \mathrm{~m}$ & $90 \%-2,1 \mathrm{~m}$ & Rendah \\
\hline$[21]$ & WLAN & Neural Network & $3 \mathrm{~m}$ & $90 \%-5,4 \mathrm{~m}$ & Rendah \\
\hline Compass [22] & WLAN & Probabilistik & $1,65 \mathrm{~m}$ & - & Rendah \\
\hline$[23]$ & WLAN & kNN & $1,45 \mathrm{~m}$ & $84 \%-2 \mathrm{~m}$ & Rendah \\
\hline OPT [24] & WSN & Laterasi & $1,5-3,8 \mathrm{~m}$ & - & Rendah \\
\hline BLPA & Bluetooth & Laterasi & $3,76 \mathrm{~m}$ & - & Rendah \\
\hline
\end{tabular}




\section{KESIMPULAN}

Informasi lokasi yang dihasilkan oleh berbagai WIPS dapat menjadi input bagi teknologi-teknologi berbasis context-awareness. Beberapa jenis informasi dapat disediakan untuk mendukung kebutuhan pengguna.

Pemilihan teknik dan teknologi positioning harus disesuaikan dengan kebutuhan dan keadaan. Misalnya, untuk menekan biaya, digunakan teknologi WLAN untuk WIPS pada lingkungan yang sudah memakainya.

Paper ini masih kurang menyajikan contoh-contoh sistem yang telah ada dengan berbagai variasi teknik, algoritma dan teknologi yang digunakan. Hal tersebut mengakibatkan kurangnya gambaran perbandingan antar sistem yang bervariasi tersebut.

\section{References}

[1] P. Prekop and M. Burnett, "Activities, context and ubiquitous computing," Comput. Commun., vol. 26, no. 11, pp. 1168-1176, 2003.

[2] B. Schilit, N. Adams, and R. Want, "Context-aware computing applications," 1994, pp. 85-90.

[3] E. Kim and J. Choi, "A Context Management System for Supporting ContextAware Applications,” 2008, vol. 2, pp. 577-582.

[4] N. Le Dortz, F. Gain, and P. Zetterberg, "WiFi fingerprint indoor positioning system using probability distribution comparison,” 2012, pp. 2301-2304.

[5] H. Liu, H. Darabi, P. Banerjee, and J. Liu, "Survey of wireless indoor positioning techniques and systems," Syst. Man, Cybern. Part C Appl. Rev. IEEE Trans., vol. 37, no. 6, pp. 1067-1080, 2007.

[6] A. M. Ladd, K. E. Bekris, A. P. Rudys, D. S. Wallach, and L. E. Kavraki, "On the feasibility of using wireless ethernet for indoor localization," IEEE Trans. Robot. Autom., vol. 20, no. 3, pp. 555-559, 2004.

[7] J. Xiao, Z. Liu, Y. Yang, D. Liu, and X. Han, "Comparison and analysis of indoor wireless positioning techniques," 2011, pp. 293-296.

[8] Y. Gu, A. Lo, and I. Niemegeers, “A survey of indoor positioning systems for 
wireless personal networks," Commun. Surv. Tutorials, IEEE, vol. 11, no. 1, pp. 13-32, 2009.

[9] Y. Wang, X. Jia, H. K. Lee, and G. Y. Li, “An indoors wireless positioning system based on wireless local area network infrastructure," 2003.

[10]H. Koyuncu and S. H. Yang, “A survey of indoor positioning and object locating systems," IJCSNS Int. J. Comput. Sci. Netw. Secur., vol. 10, no. 5, pp. 121-128, 2010.

[11] J. Hightower, G. Borriello, and H. Jeffrey, "Location systems for ubiquitous computing," Computer (Long. Beach. Calif)., vol. 34, no. 8, pp. 57-66, Aug. 2001.

[12]Z. Yang and Y. Liu, "Quality of trilateration: Confidence-based iterative localization,” Parallel Distrib. Syst. IEEE Trans., vol. 21, no. 5, pp. 631-640, 2010.

[13] J. Hightower and G. Borriello, "Location sensing techniques," IEEE Comput., vol. 34, no. 8, pp. 57-66, 2001.

[14] I. Guvenc and C.-C. Chong, "A survey on TOA based wireless localization and NLOS mitigation techniques," Commun. Surv. Tutorials, IEEE, vol. 11, no. 3, pp. 107-124, 2009.

[15] J. Zhou, H. Zhang, and L. Mo, “Two-dimension localization of passive RFID tags using AOA estimation," 2011, pp. 1-5.

[16]N. Patwari and A. O. Hero III, "Using proximity and quantized RSS for sensor localization in wireless networks,” 2003, pp. 20-29.

[17] J. Hightower, R. Want, and G. Borriello, "SpotON: An indoor 3D location sensing technology based on RF signal strength,” 2000.

[18] L. M. Ni, Y. Liu, Y. C. Lau, and A. P. Patil, "LANDMARC: Indoor Location Sensing Using Active RFID," Wirel. Networks, vol. 10, no. 6, pp. 701-710, Nov. 2004.

[19]P. Bahl and V. Padmanabhan, "RADAR: An in-building RF-based user location and tracking system," INFOCOM 2000. Ninet. ..., 2000.

[20] M. Youssef and A. Agrawala, "The Horus location determination system," Wirel. Networks, 2008. 
[21]R. Battiti, N. T. Le, and A. Villani, "Location-aware computing: a neural network model for determining location in wireless LANs," 2002.

[22] T. King, S. Kopf, T. Haenselmann, C. Lubberger, and W. Effelsberg, "Compass: A probabilistic indoor positioning system based on 802.11 and digital compasses,” 2006, pp. 34-40.

[23]E. S. Pasinggi, S. Sulistyo, and B. S. Hantono, "Sistem Penentuan Posisi Di Dalam Ruangan Dengan Metode Fingerprint ( Knn ),” pp. 6-8, 2015.

[24]X. An, J. Wang, R. V. Prasad, and I. Niemegeers, "OPT: online person tracking system for context-awareness in wireless personal network," 2006, pp. 47-54.

[25]A. Kotanen, M. Hannikainen, H. Leppakoski, and T. D. Hamalainen, "Experiments on local positioning with Bluetooth," 2003, pp. 297-303.

[26]Fahrudin Mukti Wibowo, S. Selo, and B. Hantono, "Metode Trilaterasi Untuk Penentuan Posisi Dalam Ruangan Menggunakan Bluetooth Low Energy,” 2017. 